\title{
A Review Hierarchical bayes small area estimation under an area level model with applications to horticultural survey data
}

\author{
Nageena Nazir, S. A. Mir and M. Iqbal Jeelani
}

Correspondence to :

Nageena Nazir

Division of Agri-statistics, SKUAST-K, Shalimar

(J\&K) India

Email : nazir.nageena@

gmail.com

Paper History :

Received : 01.01.2018,

Accepted : 22.02 .2018

ABSTRACT : In this paper we studied Bayesian aspect of small area estimation using Area level model. We proposed and evaluated new prior distribution for the area level model, for the variance component rather than uniform prior. The proposed model is implemented using the MCMC method for fully Bayesian inference. Laplace approximation is used to obtain accurate approximations to the posterior moments. We apply the proposed model to the analysis of horticultural data and results from the model are compared with frequestist approach and with Bayesian model of uniform prior in terms of average relative bias, average squared relative bias and average absolute bias. The numerical results obtained highlighted the superiority of using the proposed prior over the uniform prior.

KEY Words : Small area estimation, Area level model, Hierarchical bayes

How To Cite This PAper : Nazir, Nageena, Mir, S.A. and Jeelani, M. Iqbal (2018). Hierarchical bayes small area estimation under an area level model with applications to horticultural survey data. Internat. Res. J. Agric. Eco. \& Stat., 9 (1) : 215-223, DOI : 10.15740/HAS/IRJAES/9.1/215-223. 